\title{
Behavioural responses of Frankliniella occidentalis Pergande larvae to methyl jasmonate and cis-jasmone
}

\author{
Barbara Egger $\cdot$ Elisabeth H. Koschier
}

Received: 19 December 2012/ Accepted: 5 October 2013/Published online: 15 October 2013

(C) The Author(s) 2013. This article is published with open access at Springerlink.com

\begin{abstract}
The larval stages of Frankliniella occidentalis Pergande (Thysanoptera: Thripidae) cause more direct feeding damage to plants than the adults. We, therefore, investigated the behaviour-modifying effects on second instar larvae of two jasmonic acid derivatives. The artificial application of methyl jasmonate and cis-jasmone, both at $1 \%$ concentration, deterred the larvae from settling in a dual choice bean leaf disc assay. We observed a dosedependent feeding deterrence of both jasmonates and calculated the concentration required to reduce the feeding damage by $50 \%$ relative to the control treatment $\left(\mathrm{FDC}_{50}\right)$ for each jasmonate. The feeding damage was reduced by the application of cis-jasmone at $1 \%$ concentration, but not by the jasmonates at the respective $\mathrm{FDC}_{50}$ in no-choice leaf disc bioassays. However, significantly more larvae left jasmonate-treated whole potted bean plants by migrating to the soil compared with control plants. Our results may be exploited extending behavioural manipulation by using plant compounds in thrips control programmes to the full lifecycle of the pest. Plant compounds could be used in integrated and biological pest management strategies against $F$. occidentalis in combination with the application of various above and below ground control measures.
\end{abstract}

Keywords Thrips $\cdot$ Second instar $\cdot$ Secondary plant compounds · Jasmonates $\cdot$ Feeding deterrent .

Leaving behaviour

Communicated by N. Agusti.

B. Egger $(\bowtie) \cdot$ E. H. Koschier

Division of Plant Protection, Department of Crop Sciences,

University of Natural Resources and Life Sciences (BOKU),

Vienna, Austria

e-mail: barbara.egger@boku.ac.at

\section{Introduction}

Frankliniella occidentalis Pergande (Thysanoptera: Thripidae), the western flower thrips, is a major pest in agricultural and horticultural crops worldwide (Kirk and Terry 2003). The adults and larvae of this highly polyphagous pest insect feed on epidermal and sub-epidermal plant tissues, causing necrotic blotches and reducing their photosynthetic capacity. In addition, the plants are damaged indirectly by the transmission of various plant viruses (Moritz 2006). Frankliniella occidentalis exhibits a thigmotactic behaviour that makes an efficient application of chemical insecticides difficult. Furthermore, some thrips pests have developed resistance to a range of insecticides (Jensen 2000; Reitz 2009). Several beneficial organisms whose target instars are predominantly the larval instars of the thrips, e.g. predatory mites, parasitic wasps or entomopathogenic fungi, are successfully used in biological control measures or are currently investigated for thrips control (Brodsgaard 2004; Ebssa et al. 2006).

Methyl jasmonate and cis-jasmone are constituents of essential oils, for instance, from Jasminum sp., Lonicera sp. or Philadelphus sp. (Mookherjee et al. 1990; Joulain 1986). Moreover, being stress-related secondary plant compounds, both jasmonic acid derivatives are known to play a major role in plant defence mechanisms against herbivores (Birkett et al. 2000; Howe and Jander 2008). Exogenous applications of cis-jasmone or methyl jasmonate to plants in laboratory and field studies have been shown to induce plant resistance to herbivores and indirectly affected pests such as various aphid species (e.g. Bruce et al. 2003a, b; Brunissen et al. 2010; Glinwood et al. 2007; Thaler et al. 2001), the two-spotted spider mite Tetranychus urticae Koch (Rohwer and Erwin 2010) and F. occidentalis adults (Thaler et al. 2001). Furthermore, 
methyl jasmonate and cis-jasmone may act as an indirect defence mechanism of plants by attracting natural enemies of the herbivores, among them being the aphid parasitoid Aphidius ervi Haliday and other hymenopteran parasitoids (Bruce et al. 2003b; Simpson et al. 2011).

Research on the direct effects of jasmonates on herbivores is comparatively scarce. Olfactometer studies revealed repellence of $c i s$-jasmone to the grain aphid $\mathrm{Si}$ tobion avenae Fabricius (Bruce et al. 2003a, b) and the lettuce aphid Nasonovia ribis-nigri Mosley. Traps baited with $c i s$-jasmone were found repellent to the damson-hop aphid Phorodon humuli Schrank (Birkett et al. 2000), but attracted the pest thrips species New Zealand flower thrips (Thrips obscuratus Crawford) (Teulon et al. 2007) in field experiments.

In contrast, some previous findings indicate that western flower thrips adults respond negatively to jasmonates: $F$. occidentalis females avoided methyl jasmonate-treated chrysanthemum plants in the laboratory (Bruhin 2009), significantly lower numbers of thrips were found on jasmonic acid-sprayed plants in the field (Thaler et al. 2001) and jasmonate-baited traps did not attract $F$. occidentalis (James 2005). These studies in particular and most other studies on the effects of secondary plant volatiles on thrips, in general, have mainly focused on adults. Possible direct effects on larvae have yet to be researched. This topic is of considerable interest, because $F$. occidentalis larval stages usually cause more direct feeding damage than adults because of their greater abundance on a plant (Wiesenborn and Morse 1986). However, if and how the less-mobile larvae of $F$. occidentalis respond to the jasmonates is not known to date.

The aim of our study was therefore to investigate the potential deterrent effects of an application of cis-jasmone and methyl jasmonate to bean leaf discs and potted bean plants on $F$. occidentalis second instar larvae. Initially, we observed the settling preference of the larvae for treated or untreated leaf discs in choice bioassays. Second, we determined the concentration required to reduce the feeding damage by $50 \%$ relative to the control treatment $\left(\mathrm{FDC}_{50}\right)$ for either test dilution and evaluated their feeding deterrent activity to the larvae in a no-choice leaf disc assay. Finally, we investigated the larval behaviour on whole bean plants sprayed with the test dilutions.

\section{Materials and methods}

Insects and plants

Frankliniella occidentalis were reared on detached bean leaves on $1 \%$ water agar (Agar, Sigma-Aldrich, Vienna, Austria) in plastic Petri dishes (14-cm diameter) in a climate chamber at $24 \pm 1{ }^{\circ} \mathrm{C}, 45 \pm 5 \%$ relative humidity and a L16:D8 photoperiod. The dishes were closed with lids with central holes covered with a fine mesh to ensure ventilation. To obtain groups of second instar larvae of known age for the bioassays, $F$. occidentalis females were allowed to lay eggs on bean leaves in separate Petri dishes for $24 \mathrm{~h}$. The larvae were used for testing 5-6 days after the end of the oviposition.

Bean plants (Phaseolus vulgaris, var. Borlotto) used for rearing as well as for testing were grown in a plant growing room at $25 \pm 1{ }^{\circ} \mathrm{C}$, at $50 \pm 5 \%$ relative humidity and at a L16:D8 photoperiod in groups of 13-15 plants per pot. Leaf discs used for the bioassays were punched from fully developed leaves of 11-13 days old bean plants by means of a cork borer. The potted bean plants were grown singly and were used for the experiment after having fully developed both primary leaves.

\section{Application of compounds}

The test compounds methyl jasmonate ( $\geq 95 \%$, SigmaAldrich, Vienna, Austria) and cis-jasmone ( $\geq 85 \%$, SigmaAldrich, Vienna, Austria) were diluted in pure ethanol (Merck, Darmstadt, Germany) at a ratio of 1:10 and in a relative quantity of distilled water mixed with a surfactant $(0.05 \%$ Triton X-100, Sigma-Aldrich, Vienna, Austria) to obtain a range of concentrations $(0.1-1 \%)$. The control solution consisted of ethanol (Merck, Darmstadt, Germany) and distilled water with the surfactant $(0.05 \%$ Triton X-100, Sigma-Aldrich, Vienna, Austria) at a ratio of 1:10.

For the leaf disc bioassays, the bean leaf discs were sprayed with the respective solution using a Potter Precision Laboratory Spray Tower (Burkard Manufacturing Co Ltd., Rickmansworth, UK) resulting in a solution quantity on the leaf of about $1 \mu \mathrm{l} / \mathrm{cm}^{2}$. The treated leaf discs were allowed to dry for approximately $10 \mathrm{~min}$ and subsequently placed on $1 \%$ water agar (Fluka Analytical, SigmaAldrich, Vienna, Austria) droplets in a Petri dish to prevent the leaf discs from wilting. After releasing the test insects, the bioassay units were closed with a plastic sealing film (Carl Roth, Karlsruhe, Germany) which was perforated subsequently with insect pins to ensure ventilation (approximately 10 holes per $\mathrm{cm}^{2}$ ).

The upper and lower leaf surfaces of the whole bean plants used for the larval leaving bioassays were sprayed with a total amount of $2.5 \mathrm{ml}$ of methyl jasmonate, cisjasmone (either at the $\mathrm{FDC}_{50}$, see below) or control solution per plant by means of an airbrush (DeVilbiss, Bournemouth, UK) resulting in a similar solution quantity to the one for the leaf disc assay. The solution quantity was determined by comparing the spray distributions of the potter spray tower and the airbrush using water-sensitive paper (Syngenta, Basel, Switzerland). The solutions were 
allowed to dry for approximately $10 \mathrm{~min}$ before releasing the test insects.

\section{Settlement preference}

Choice experiments were conducted to test for settlement preferences of $F$. occidentalis larvae at $1 \%$ compound concentration. A control bean leaf disc and a treated leaf disc (1.6-cm diameter each) were placed at a distance of approximately $4 \mathrm{~cm}$ to each other on two $350 \mu \mathrm{l}$ water agar droplets in a glass Petri dish (6-cm diameter) to prevent the leaf discs from wilting. A group of $10 \mathrm{~F}$. occidentalis second instar larvae was released in the centre of the Petri dish. The dish was sealed with a perforated plastic sealing film as described above. After $30 \mathrm{~min}, 1,2,3,4,5$ and $6 \mathrm{~h}$ the positions of the larvae on either leaf disc or elsewhere in the Petri dish were recorded. Each treatment was replicated with 12-14 groups of larvae.

Feeding deterrence index

In a choice bioassay, a control bean leaf disc and a treated leaf disc (1.1-cm diameter each) were placed on two $350 \mu \mathrm{l}$ water agar droplets in a glass Petri dish (6-cm diameter) at a distance of approximately $4 \mathrm{~cm}$ to each other to prevent the leaf discs from wilting. A single second instar larva was released in the centre of the Petri dish. The dish was sealed with a perforated plastic sealing film as described above. After $24 \mathrm{~h}$, the larva was removed, and the feeding damage was measured using a transparent counting grid $(0.25 \times 0.25 \mathrm{~mm})$ and a stereo microscope. This procedure was repeated with four different concentrations $(0.1,0.25$, 0.5 and $1 \%$ ) of each test compound for calculating a feeding deterrence index (FDI) using the formula:

$\mathrm{FDI}=100[(C-T) /(C+T)]$

where $C$ and $T$ are the control and treated leaf areas damaged by the larvae (Isman et al. 1990). The bioassay was replicated 25-35 times per concentration for each compound.

\section{Assessment of feeding damage}

For this bioassay, a single leaf disc (1.6-cm diameter) treated either with methyl jasmonate, cis-jasmone (both at the respective $\mathrm{FDC}_{50}$ or at $1 \%$ concentration) or control solution was placed on a $700 \mu \mathrm{l}$ water agar droplet in a glass Petri dish (6-cm diameter) to prevent the leaf discs from wilting. A group of $10 \mathrm{~F}$. occidentalis second instar larvae was released on the leaf disc, and the dish was sealed with a perforated plastic sealing film as described above. After $24 \mathrm{~h}$, the larvae were removed, the feeding damage was measured using a transparent counting grid
$(0.25 \times 0.25 \mathrm{~mm})$ and a stereo microscope and subsequently converted into the percentage of damaged area on the leaf discs. The test was replicated with 13-14 groups of larvae per treatment.

\section{Larval leaving behaviour}

A bioassay adapted from Teerling et al. (1993) was conducted to test the hypothesis that $F$. occidentalis larvae would reject a jasmonate treated plant by leaving it. Black cardboards $(20 \times 20 \mathrm{~cm})$ coated with a sprayable insect trapping adhesive (Souverode, Witasek Pflanzenschutz $\mathrm{GmbH}$, Austria) covered the pots for entrapping larvae that drop from the plant. In addition, insect glue (Raupenleim, Stähler Austria GmbH \& Co KG, Austria) was applied around the stem $2 \mathrm{~cm}$ above and below the leaf nodes for trapping the larvae that leave the plants by walking down the stem. Groups of $30 \mathrm{~F}$. occidentalis second instar larvae per plant were released on the leaves using a fine brush. After keeping the differently treated plants for $24 \mathrm{~h}$ in separate climate chambers at $24 \pm 1{ }^{\circ} \mathrm{C}, 45 \pm 5 \%$ relative humidity and a L16:D8 photoperiod, larvae on the adhesive and on the plant were counted. The bioassay was replicated with eight plants per treatment.

\section{Statistical analysis}

$T$ tests were performed to compare the numbers of settled larvae and the area of feeding damage on the leaf discs. The FDI was calculated using the mean feeding damage at four different concentrations of each compound. $\mathrm{FDC}_{50}$ (the concentration that reduced feeding damage on the treated leaf disc by $50 \%$ compared with the control leaf disc) was calculated via linear regression of percentage feeding deterrence after log-transforming the concentrations for the line of best fit (Seffrin et al. 2010). Data on larvae leaving treated or untreated plants were analysed using a one-way ANOVA and a Bonferroni post hoc test. All statistical analyses were performed using the statistical software PASW 18.0.0 (SPSS Inc., USA).

\section{Results}

Settlement preference

The number of $F$. occidentalis larvae settling on one of the two leaf discs in the bioassay unit gradually increased: After 30 min, more than $30 \%$ of the larvae had chosen one of the leaf discs in the methyl jasmonate bioassay unit, whereas after $6 \mathrm{~h}$, about $70 \%$ of the larvae had settled on one of the leaf discs (Fig. 1a). Similarly, $37 \%$ of the larvae had chosen one of the leaf discs in the cis-jasmone bioassay 

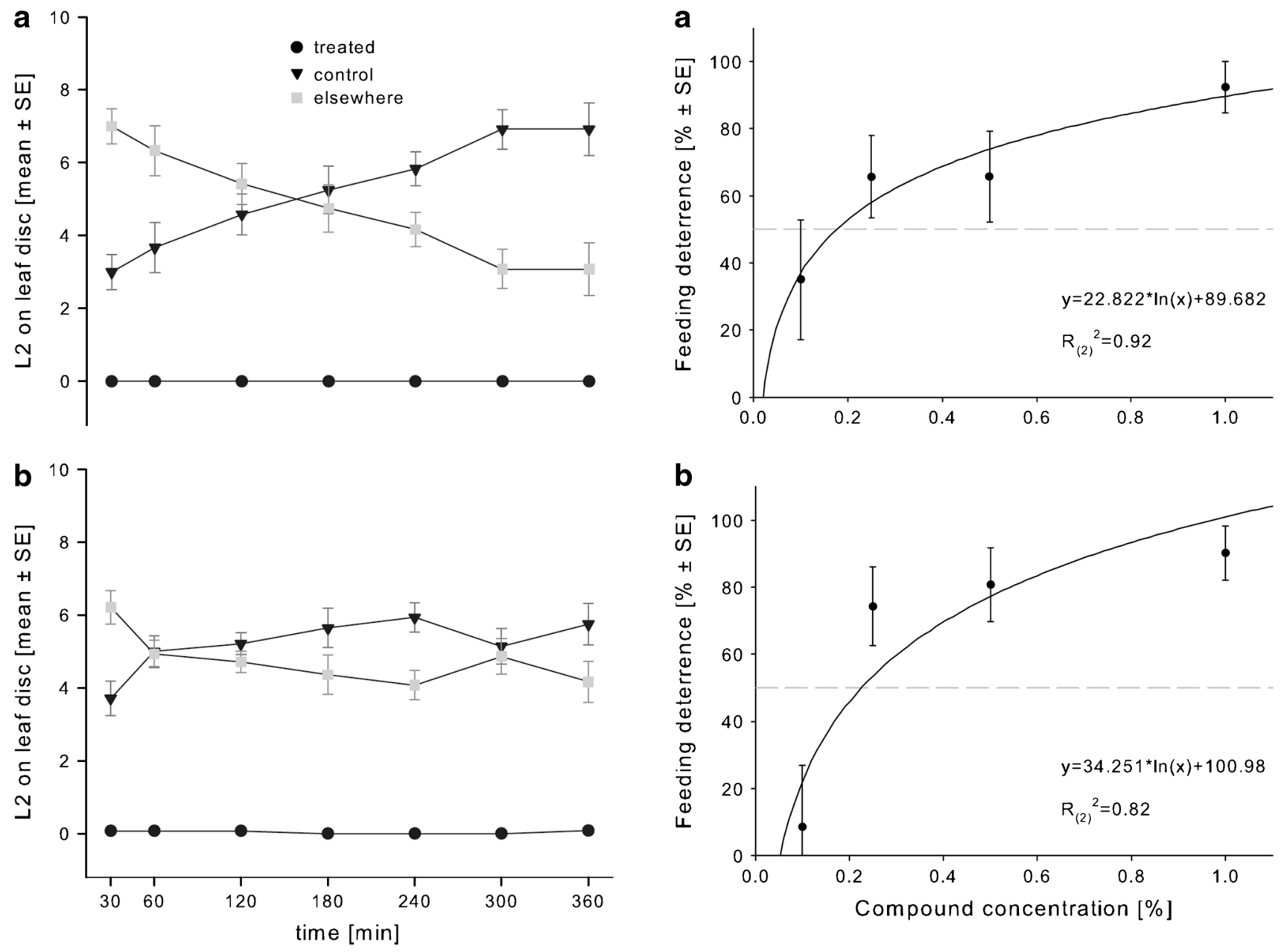

Fig. 1 Mean number $( \pm \mathrm{SE})$ of settled $F$. occidentalis second instar larvae on either control leaf discs, treated leaf disc or elsewhere in the bioassay unit. Dual choice bioassay with leaf discs treated with a methyl jasmonate or $\mathbf{b}$ cis-jasmone (both at $1 \%$ ) and a control leaf disc. Settlement preference recorded at $30 \mathrm{~min}, 1,2,3,4,5$ and $6 \mathrm{~h}$ after the release of groups of $10 \mathrm{~F}$. occidentalis second instar larvae per unit, 12-14 groups tested

unit after $30 \mathrm{~min}$, whereas after $6 \mathrm{~h}$, about $60 \%$ of the larvae had settled on one of the leaf discs (Fig. 1b).

Either jasmonate applied at $1 \%$ concentration exhibited a highly significant deterrent effect on the $F$. occidentalis larvae (Fig. 1). At the most one larva per bioassay unit was counted on the leaf disc treated with $c i s$-jasmone (paired $t$ test, $P<0.001$ ). Methyl jasmonate-treated leaf discs were avoided by the larvae at any of the observed points in time (paired $t$ test, $P<0.001$ ).

Feeding deterrence

The feeding deterrent effect of methyl jasmonate, as well as those of cis-jasmone on $F$. occidentalis larvae, was positively correlated with increasing compound concentrations (Fig. 2). The $\mathrm{FDC}_{50}$, i.e. the concentration that

Fig. 2 Mean feeding deterrence of a methyl jasmonate and $\mathbf{b}$ cisjasmone to $F$. occidentalis second instar larvae at increasing concentrations in a choice bioassay

reduced the feeding damage by $50 \%$ on a treated leaf disc, was determined at about $0.18 \%$ for methyl jasmonate and at about $0.23 \%$ for cis-jasmone.

Leaf discs treated with $1 \%$ cis-jasmone reduced feeding damage caused by the larvae in the no-choice situation (unpaired $t$ test, $T_{(30)}=3.685, P<0.01$ ); however, neither the application of $1 \%$ methyl jasmonate nor of either test dilution at the respective $\mathrm{FDC}_{50}$ reduced the feeding damage on treated leaf discs compared with the untreated leaf discs (Fig. 3).

Larval leaving behaviour

The treatment of bean plants with methyl jasmonate or cisjasmone at 0.18 or $0.23 \%$ concentration $\left(\mathrm{FDC}_{50}\right)$, respectively caused the $F$. occidentalis larvae to leave the plants. After $24 \mathrm{~h}$, significantly more larvae were found on the sticky cardboards underneath the jasmonate-treated plants compared to the control plants (one-way ANOVA, $\left.\mathrm{F}_{(2,21)}=20.305, P<0.001\right)$. While about $30 \%$ of the 


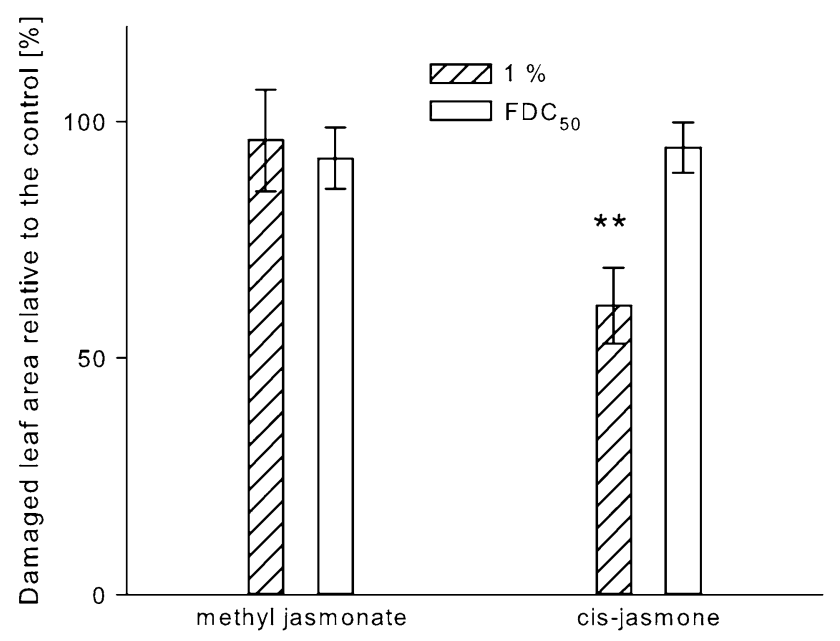

Fig. 3 Percentage of damaged area $( \pm S E)$ caused by the feeding activity of $F$. occidentalis second instar larvae on leaf discs treated with methyl jasmonate or $c i s$-jasmone (both at $1 \%$ or $\mathrm{FDC}_{50}$ ) relative to the damaged area of control leaf discs in a no-choice test within $24 \mathrm{~h}$. Means are significantly different at ${ }^{*} P P<0.01$; unpaired $t$ test

Table 1 Mean number $( \pm \mathrm{SE})$ per plant of $F$. occidentalis second instar larvae leaving bean plants treated with the concentration required to reduce the feeding damage by $50 \%\left(\mathrm{FDC}_{50}\right)$ of methyl jasmonate, respectively cis-jasmone and the control solution within 24 h. 30 larvae were released per plant

\begin{tabular}{lccc}
\hline Treatment & \multicolumn{3}{l}{ Number of larvae leaving the plant } \\
\cline { 2 - 4 } & \multicolumn{2}{c}{ Mean } & \pm SE \\
\hline Control & 3.25 & \pm 0.49 & A \\
Methyl jasmonate $0.18 \%$ & 9.25 & \pm 0.63 & B \\
Cis-jasmone $0.23 \%$ & 10.13 & \pm 0.73 & B \\
\hline
\end{tabular}

Values followed by different letters are significantly different (oneway ANOVA, Bonferroni)

larvae left the methyl jasmonate or cis-jasmone-treated plants, only about $11 \%$ left the control plants (Table 1).

\section{Discussion}

We focussed our study on $F$. occidentalis second instar larvae because, due to their high abundance and feeding commitment, the immature stages are responsible for a large part of the direct feeding damage on plants (Wiesenborn and Morse 1986). As far as we know, only one study with antifeedants was carried out with thrips larvae so far: carvacrol and thymol, two monoterpenoid phenols, applied to the test plants at a concentration of $1 \%$ deterred $F$. occidentalis second instar larvae in choice bioassays. In addition, the feeding damage of the larvae was reduced in a no-choice situation (Peneder and Koschier 2011).
In the first step, we used cis-jasmone and methyl jasmonate both at $1 \%$ concentration in choice settlement assays to examine these substances for potential deterrent effects since this compound concentration proved to be efficient to screen for other potential deterrent substances in earlier studies (Koschier et al. 2007; Riefler and Koschier 2009). We identified both jasmonates as deterrents to the larvae: At each point of time during the observation, more than $90 \%$ of the larvae avoided contact with the jasmonate-treated leaf discs. This highly significant settlement preference for the control leaf discs suggests that, although $F$. occidentalis larvae are not the host seeking instar (Terry 1997), they are able to respond to deterrents applied to leaf discs.

In the second step, we determined a feeding deterrent index to detect the range of effectiveness of the jasmonates. In the present study both jasmonates proved to be dosedependent deterrents to thrips larvae. The calculation of the $\mathrm{FDC}_{50}$, the deterrent concentration required to reduce feeding damage by $50 \%$ relative to the control, allows a direct comparison of the effectiveness of different compounds. However, the feeding damage was not reduced after the application of the $\mathrm{FDC}_{50}$ of either jasmonate when the larvae had no choice. Only a relatively high $1 \%$ concentration resulted in a reduction of the feeding damage after the application of $c i$-jasmone. This suggests that the commitment to feeding of second instar larvae exceeds the deterrent effect of the jasmonates at lower concentrations when there is no alternative food source available. On a whole treated plant, the larvae would have the alternative choice of leaving the plant and migrating to the soil.

Experiments with potted bean plants revealed that more than $90 \%$ of $F$. occidentalis choose the soil as pupation site as late second instar larvae (Berndt et al. 2004a). Deterrent plant compounds applied to their host plants might cause the larvae to leave the treated plant earlier during their development, thus reducing the feeding damage caused by the larvae. After the application of the synthetic thrips alarm pheromone dodecyl-acetate dropping rates of 5-15\%, depending on the method of application, were reported (Teerling et al. 1993). In our study, we achieved dropping rates of about $30 \%$ after the application of the jasmonates, whereas about $10 \%$ left the control plants, presumably to search for an appropriate pupation site in the soil.

We located the larvae that had left the plants on the sticky cardboard traps, but not on the stems coated with adhesive. Therefore, we assume that the larvae dropped to the cardboards, i.e. the soil, rather than walked down the stem towards the soil.

The increased leaving rates indicate that the jasmonates could be integrated in thrips control strategies, for instance, as synergists in the context of push-pull strategies or 
biological control strategies. Efficient biological control measures against soil-dwelling thrips stages are the application of entomopathogenic fungi Beauveria bassiana Balsamo and Metarhizium anisopliae Metsch (Ansari et al. 2008; Ugine et al. 2005), soil-dwelling predatory mites Hypoaspis sp. and Stratiolaelaps miles Berlese (Berndt et al. 2004a, b), and entomopathogenic nematodes (Ebssa et al. 2004). Since the $F$. occidentalis larvae are the main target instar for predators and parasitoids, an additional possible synergistic effect of jasmonate application could be the attraction of various above-ground beneficial insects, among them being some hymenopterous parasitoids of thrips (Birkett et al. 2000; Bruce et al. 2003a; James and Grasswitz 2005; James 2005; Simpson et al. 2011; Thaler 1999). Steiner et al. (2011) revealed that the number of thrips larvae dropping from the plants decreased at a relative humidity of over $81 \%$. The manipulation of the relative humidity could be combined with the application of deterrents and measures against the soil dwelling thrips instars.

Our study is the first to demonstrate larval plant-leaving behaviour after the artificial application of secondary plant volatiles. Methyl jasmonate and cis-jasmone exhibit a deterrent effect to $F$. occidentalis second instar larvae and cause the larvae to leave bean plants, presumably by dropping to the soil. These direct and indirect effects may be exploited in integrated and biological pest management strategies by combining them with other control measures. Further investigation on the influence of jasmonates on the thrips metabolism, on behavioural responses of adult $F$. occidentalis to volatile jasmonates and the potential of artificial jasmonate treatments to induce plant defence mechanisms against Thysanoptera are necessary to evaluate the future role of jasmonates in thrips control strategies.

Acknowledgments The authors thank Stefan Peneder for the assistance in the laboratory and Bernhard Spangl for his valuable comments on statistical topics. This project was financially supported by the Austrian Science Fund (FWF project P23160-B16).

Open Access This article is distributed under the terms of the Creative Commons Attribution License which permits any use, distribution, and reproduction in any medium, provided the original author(s) and the source are credited.

\section{References}

Ansari MA, Brownbridge M, Shah FA, Butt TM (2008) Efficacy of entomopathogenic fungi against soil-dwelling life stages of western flower thrips, Frankliniella occidentalis, in plant-growing media. Entomol Exp Appl 127:80-87

Berndt O, Meyhöfer R, Poehling H-M (2004a) The edaphic phase in the ontogenesis of Frankliniella occidentalis and comparison of Hypoaspis miles and Hypoaspis aculeifer as predators of soildwelling thrips stages. Biol Control 30:17-24
Berndt O, Poehling HM, Meyhöfer R (2004b) Predation capacity of two predatory laelapid mites on soil-dwelling thrips stages. Entomol Exp Appl 112:107-115

Birkett MA, Campbell CAM, Chamberlain K, Guerrieri E, Hick AJ, Martin JL, Matthes M, Napier JA, Pettersson J, Pickett JA, Poppy GM, Pow EM, Pye BJ, Smart LE, Wadhams GH, Wadhams LJ, Woodcock CM (2000) New roles for cis-jasmone as an insect semiochemical and in plant defense. P Natl Acad Sci USA 97:9329-9334

Brodsgaard HF (2004) Biological control of thrips on ornamental crops. In: Heinz KM, Van Driesche RG, Parrella MP (eds) Biocontrol in protected culture. Ball Publishing, Batavia, pp 253-264

Bruce TJA, Martin JL, Pickett JA, Pye BJ, Smart LE, Wadhams LJ (2003a) cis-Jasmone treatment induces resistance in wheat plants against the grain aphid, Sitobion avenae (Fabricius) (Homoptera : Aphididae). Pest Manag Sci 59:1031-1036

Bruce TJA, Pickett JA, Smart LE (2003b) cis-jasmone switches on plant defence against insects. Pestic Outlook 52:96-98

Bruhin D (2009) Direct and indirect effects of methyl salicylate and methyl jasmonate on Frankliniella occidentalis Pergande on pot chrysanthemum. Master thesis, Wien: Univ. für Bodenkultur

Brunissen L, Vincent C, Le Roux V, Giordanengo P (2010) Effects of systemic potato response to wounding and jasmonate on the aphid Macrosiphum euphorbiae (Sternorryncha: Aphididae). J Appl Entomol 134(7):562-571

Ebssa L, Borgemeister C, Poehling HM (2004) Effectiveness of different species/strains of entomopathogenic nematodes for control of western flower thrips (Frankliniella occidentalis) at various concentrations, host densities, and temperatures. Biol Control 29:145-154

Ebssa L, Borgemeister C, Poehling HM (2006) Simultaneous application of entomopathogenic nematodes and predatory mites to control western flower thrips Frankliniella occidentalis. Biol Control 39:66-74

Glinwood R, Gradin T, Karpinska B, Ahmed E, Jonsson L, Ninkovic V (2007) Aphid acceptance of barley exposed to volatile phytochemicals differs between plants exposed in daylight and darkness. Plant Signal Behav 2:321-326

Howe GA, Jander G (2008) Plant immunity to insect herbivores. Annu Rev Plant Biol 59:41-66

Isman MB, Koul O, Luczynski A, Kaminski J (1990) Insecticidal and antifeedant bioactivities of neem oils and their relationship to azadirachtin content. J Agr Food Chem 38:1406-1411

James DG (2005) Further field evaluation of synthetic herbivoreinduced plant volatiles as attractants for beneficial insects. J Chem Ecol 31:481-495

James DG, Grasswitz T (2005) Synthetic herbivore-induced plant volatiles increase field captures of parasitic wasps. Biocontrol 50:871-880

Jensen SE (2000) Insecticide resistance in the western flower thrips, Frankliniella occidentalis. Int Pest Manag Rev 5:131-146

Joulain D (1986) Study of the fragrance given off by certain springtime flowers. In: Brunke E-J (ed) Progress in essential oil research. Walter de Gruyter, Berlin, pp 57-68

Kirk WDJ, Terry LI (2003) The spread of the western flower thrips Frankliniella occidentalis (Pergande). Agr Forest Entomol 5: 301-310

Koschier EH, Hoffmann D, Riefler J (2007) Influence of salicylaldehyde and methyl salicylate on post-landing behaviour of Frankliniella occidentalis Pergande. J Appl Entomol 131: 362-367

Mookherjee BD, Trenkle RW, Wilson RA (1990) The chemistry of flowers, fruits and spices: live vs. dead - a new dimension in fragrance research. Pure Appl Chem 62:1357-1364 
Moritz G (2006) Thripse : Fransenflügler, Thysanoptera. 1. Aufl. edition. Westarp Wissenschaften, Hohenwarsleben

Peneder S, Koschier EH (2011) Toxic and behavioural effects of carvacrol and thymol on Frankliniella occidentalis larvae. J Plant Dis Protect 118:26-30

Reitz SR (2009) Biology and ecology of the western flower thrips (Thysanoptera: Thripidae): The making of a pest. Fla Entomol 92:7-13

Riefler J, Koschier EH (2009) Behaviour-modifying activity of eugenol on Thrips tabaci Lindeman. J Pest Sci 82:115-121

Rohwer CL, Erwin JE (2010) Spider mites (Tetranychus urticae) perform poorly on and disperse from plants exposed to methyl jasmonate. Entomol Exp Appl 137:143-152

Seffrin RD, Shikano I, Akhtar Y, Isman MB (2010) Effects of crude seed extracts of Annona atemoya and Annona squamosa L. against the cabbage looper, Trichoplusia $n i$ in the laboratory and greenhouse. Crop Prot 29:20-24

Simpson M, Gurr GM, Simmons AT, Wratten SD, James DG, Leeson G, Nicol HI, Orre-Gordon GUS (2011) Attract and reward: combining chemical ecology and habitat manipulation to enhance biological control in field crops. J Appl Ecol 48: 580-590

Steiner MY, Spohr LJ, Goodwin S (2011) Relative humidity controls pupation success and dropping behaviour of western flower thrips, Frankliniella occidentalis (Pergande) (Thysanoptera: Thripidae). Aust J Entomol 50(2):179-186
Teerling CR, Pierce HD Jr, Borden JH, Gillespie DR (1993) Identification and bioactivity of alarm pheromone in the western flower thrips, Frankliniella occidentalis. J Chem Ecol 19: $681-697$

Terry LI (1997) Host selection, communication and reproductive behaviour. In: Lewis $\mathrm{T}$ (ed) Thrips as crop pests. CAB International, Oxon, pp 65-118

Teulon DAJ, Davidson MM, Hedderley DI, James DE, Fletcher CD, Larsen L, Green VC, Perry NB (2007) 4-Pyridyl carbonyl and related compounds as thrips lures: effectiveness for onion thrips and New Zealand flower thrips in field experiments. J Agr Food Chem 55:6198-6205

Thaler JS (1999) Jasmonate-inducible plant defences cause increased parasitism of herbivores. Nature 399:686-688

Thaler JS, Stout MJ, Karban R, Duffey SS (2001) Jasmonatemediated induced plant resistance affects a community of herbivores. Ecol Entomol 26:312-324

Ugine TA, Wraight SP, Brownbridge M, Sanderson JP (2005) Development of a novel bioassay for estimation of median lethal concentrations (LC50) and doses (LD50) of the entomopathogenic fungus Beauveria bassiana, against western flower thrips, Frankliniella occidentalis. J Invertebr Pathol 89:210-218

Wiesenborn WD, Morse JG (1986) Feeding rate of Scirtothrips citri (Moulton) (Thysanoptera: thripidae) as influenced by life stage and temperature. Environ Entomol 15(3):763-766 